\title{
A EDUCAÇÃO EM SAÚDE NA PRÁTICA PROFISSIONAL DO ENFERMEIRO: REVISÃO NARRATIVA
}

\author{
Lucas Corrêa Preis ${ }^{1}$ \\ Giseli Orben ${ }^{2}$ \\ Simara Medeiros Martins ${ }^{3}$ \\ Greice Lessa 4 \\ Karla Pickler Cunha ${ }^{5}$
}

\section{INTRODUÇÃO}

Surgida no ano de 1909, a educação em saúde teve como objetivo central uma estratégia emergente de prevenção de doenças, por meio de um esforço individual e a adesão a hábitos de vida saudáveis. Foi norteada pelo melhoramento dos conhecimentos da população de modo a distanciamento dos hábitos não saudáveis, bem como, transmissão de conhecimentos por meio de conteúdos neutros, claros e de fácil entendimento para a domesticação da população por meio das regras impostas pelos trabalhadores da área da saúde (ALVES; AERTS, 2011).

Atualmente, a educação em saúde é considerada uma importante ferramenta para a conscientização da população de forma individual e coletiva quanto à importância de um adequado cuidado a sua saúde, responsabilizando-os por seus hábitos e atos, transformando-se em uma essencial atividade para formulação de politicas, bem como, desenvolvimento de ações voltadas a saúde da comunidade (FERREIRA et al., 2014).

Em meio a isso, a educação em saúde torna-se um processo amplo, constituindo-se em um espaço para a construção e a veiculação de saberes e práticas relacionadas com o modo de viver saudável de cada cultura, disseminandose as práticas desenvolvidas pela comunidade e assim promovendo o autocuidado (GIJSEN; KAISER, 2013).

Neste sentido, o âmbito da atenção primária em saúde tem-se como o melhor espaço para o desenvolvimento do processo educativo na saúde, uma vez

\footnotetext{
${ }^{1}$ Graduando de Enfermagem. UNIBAVE, Orleans, SC. E-mail: lucaspreis@yahoo.com.

${ }^{2}$ Graduanda de Enfermagem. UNIBAVE, Orleans, SC. E-mail: gisele riof@hotmail.com.

${ }^{3}$ Graduanda de Enfermagem. UNIBAVE, Orleans, SC. E-mail: simara-@hotmail.com.

${ }^{4}$ Doutoranda de Enfermagem. UFSC, Florianópolis, SC. E-mail: greicelessa@hotmail.com.

${ }^{5}$ Mestranda em Saúde Coletiva. UNESC, Criciúma, SC. E-mail: enfermagem@unibave.net.
} 
que, foi estruturada de forma que integrasse profissionais e comunidade, na busca de uma maior atuação e atenção aos agravos e possíveis agravos à saúde, possibilitando o desenvolvimento de ações de caráter individual e coletivo para a mudança de hábitos de vida desfavoráveis (OLIVEIRA; SANTOS, 2011).

Neste contexto, o enfermeiro é o profissional mais bem preparado para o desenvolvimento da educação em saúde, uma vez que durante seu processo de formação, é envolvido e direcionado para o desenvolvimento da gestão de seu serviço, bem como, levado ao desenvolvimento de uma assistência efetiva e de qualidade que o permita analisar a situação de uma pessoa, família ou comunidade, levantando as suas necessidades e os orientando para uma vida com mais saúde e qualidade de vida (VIANA et al., 2015).

Com base nisso, este artigo tem por objetivo identificar por meio da literatura produzida, a forma como o trabalho de educação em saúde esta inserido no contexto de trabalho do profissional enfermeiro.

\section{METODOLOGIA}

Trata-se de estudo de revisão narrativa de literatura, baseada em leituras exploratórias e seletivas do material do estudo, contribuindo para o processo de síntese e análise dos resultados. Inicialmente identificaram-se os Descritores em Ciências da Saúde através do endereço eletrônico "http://decs.bvs.brl". Posteriormente, foi realizada a busca bibliográfica na base de dados da Biblioteca Virtual em Saúde (BVS), através do endereço eletrônico "http://bvsalud.org/".

Os critérios para seleção das publicações foram: relacionarem-se com práticas educativas envolvendo o profissional enfermeiro; pesquisas que abordassem a temática de educação em saúde frente ao serviço de atenção primária; pesquisas realizadas por e/ou com enfermeiros; estarem disponíveis na integra; e serem publicadas em português.

O levantamento bibliográfico foi realizado no mês de março de 2016. Utilizou-se os Descritores em Ciências da Saúde digitando-se, na primeira linha, papel do profissional de enfermagem e, na segunda linha, educação em saúde, acrescentando-se na terceira linha atenção primária à saúde.

Durante a análise dos trabalhos, iniciou-se a leitura dos títulos, seguida da leitura dos resumos e posteriormente dos textos completos. Foram excluídos os 
artigos repetidos e suprimidas as publicações em outro idioma que não seja português, além dos estudos que não contemplassem o objetivo proposto para a temática do estudo. Destaca-se que a aplicação dos critérios de exclusão foi realizada em todas as etapas, sempre por consenso de dois leitores e que os artigos selecionados são de domínio público, com acesso disponível pela rede mundial de computadores.

\section{RESULTADOS E DISCUSSÃO}

Utilizando os descritores papel do profissional de enfermagem, educação em saúde e atenção primária à saúde na base de dados da BVS, chegou-se a 615 publicações em 07 bancos de dados diferentes, dos quais 21 artigos foram selecionados para a extração dos dados.

A partir das 21 publicações selecionadas, aplicaram-se novamente os critérios de exclusão e eliminou-se 17 publicações, sendo a pesquisa realizada com 04 publicações científicas indexadas em periódicos nacionais entre os anos de 2011 a 2013, que contemplavam o objetivo proposto pela pesquisa (Figura 1).

No Quadro 1 estão apresentados os dados referentes à autoria, ano de publicação, período de estudo e local, bem como: título do artigo, nome da revista, revisão teórica e estratégias metodológicas utilizadas.

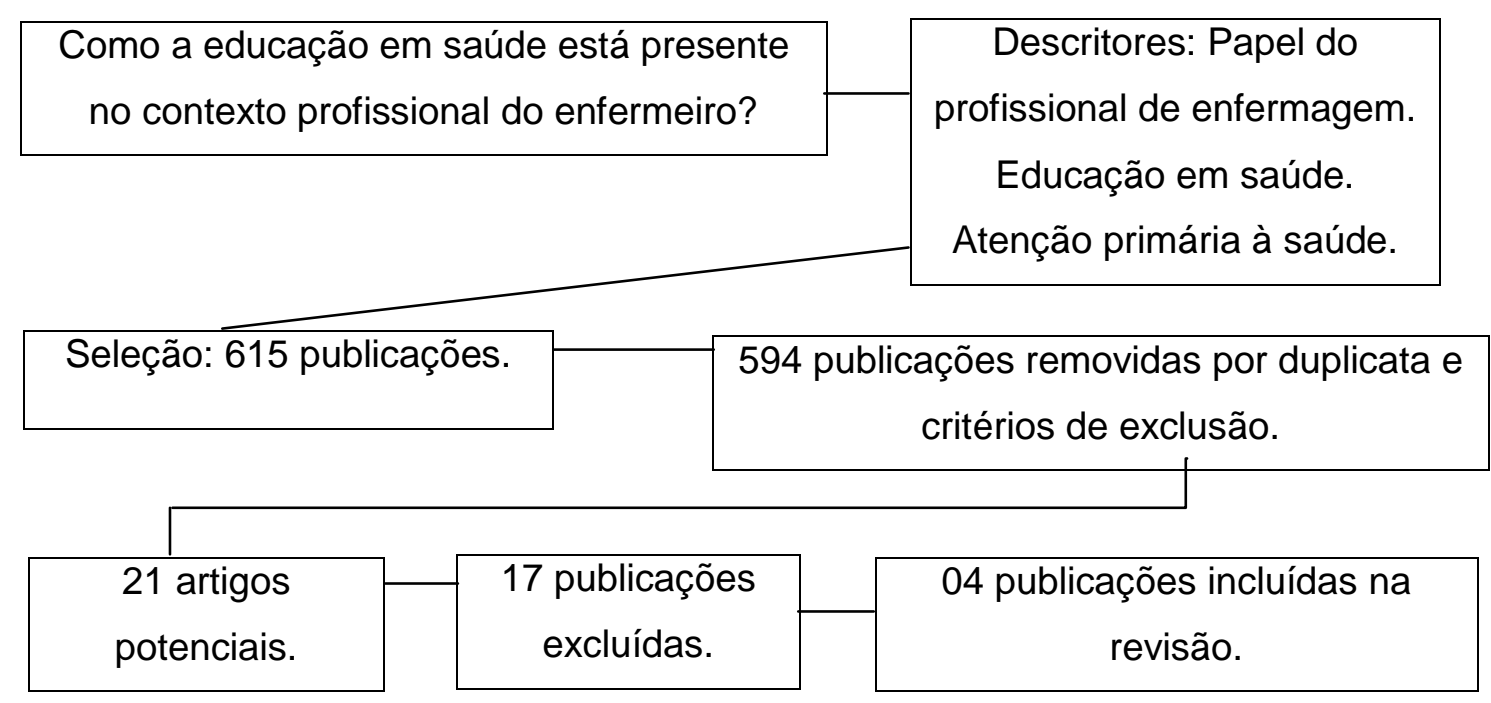

Figura 1 - Fluxograma de seleção dos trabalhos selecionados. Orleans-SC, 2016. 
Quadro 1 - Descrição dos estudos sobre a educação em saúde no contexto de trabalho do profissional enfermeiro. Orleans-SC, 2016.

\begin{tabular}{|c|c|c|c|c|}
\hline $\begin{array}{c}\text { Autor/Ano } \\
\text { Período/Local }\end{array}$ & $\begin{array}{l}\text { Titulo do } \\
\text { Artigo }\end{array}$ & $\begin{array}{l}\text { Nome da } \\
\text { Revista }\end{array}$ & Revisão Teórica & $\begin{array}{c}\text { Estratégias } \\
\text { metodológicas }\end{array}$ \\
\hline $\begin{array}{l}\text { Silva; } \\
\text { Oliveira; } \\
\text { Spinola; } \\
\text { Poleto; } \\
2011 . \\
2007-2007 . \\
\text { Brasil }\end{array}$ & $\begin{array}{l}\text { Atividades } \\
\text { desenvolvidas } \\
\text { por enfermeiros } \\
\text { no PSF e } \\
\text { dificuldades em } \\
\text { romper o } \\
\text { modelo } \\
\text { flexneriano. }\end{array}$ & $\begin{array}{c}\text { Revista de } \\
\text { Enfermagem } \\
\text { do Centro } \\
\text { Oeste Mineiro }\end{array}$ & $\begin{array}{l}\text { A educação em saúde no âmbito } \\
\text { da atenção primária é de grande } \\
\text { relevância, considerando-se o local } \\
\text { mais adequado para sua execução. } \\
\text { Porém, seu desenvolvimento é } \\
\text { esbarrado na demanda expressiva } \\
\text { de trabalho administrativo e } \\
\text { burocrático, fazendo com que, a } \\
\text { assistência predominante } \\
\text { atualmente seja curativa. }\end{array}$ & $\begin{array}{c}\text { Estudo } \\
\text { descritivo e } \\
\text { exploratório. }\end{array}$ \\
\hline $\begin{array}{l}\text { Roecker; } \\
\text { Budó; } \\
\text { Marcon; } \\
2012 . \\
\text { Brasil. }\end{array}$ & $\begin{array}{l}\text { Trabalho } \\
\text { educativo do } \\
\text { enfermeiro na } \\
\text { Estratégia } \\
\text { Saúde da } \\
\text { Família: } \\
\text { dificuldades e } \\
\text { perspectivas de } \\
\text { mudanças. } \\
\end{array}$ & $\begin{array}{c}\text { Rev Esc } \\
\text { Enferm USP }\end{array}$ & $\begin{array}{l}\text { No contexto da ESF, a educação } \\
\text { em saúde é imprescindível no } \\
\text { processo de trabalho das equipes. } \\
\text { É de suma importância que o } \\
\text { enfermeiro conheça a sua área de } \\
\text { abrangência para r o } \\
\text { desenvolvimento dela, refletindo na } \\
\text { melhora da qualidade de vida de } \\
\text { sua comunidade. }\end{array}$ & $\begin{array}{c}\text { Estudo } \\
\text { descritivo e } \\
\text { exploratório. }\end{array}$ \\
\hline $\begin{array}{l}\text { Silva; } \\
\text { Beck; } \\
\text { Dissen; } \\
\text { Tavares; } \\
\text { Budó; } \\
\text { Silva; } \\
2012 . \\
2011-2011 . \\
\text { Brasil. }\end{array}$ & $\begin{array}{l}\text { O enfermeiro e } \\
\text { a educação em } \\
\text { saúde: um } \\
\text { estudo } \\
\text { bibliográfico }\end{array}$ & $\begin{array}{l}\text { Rev Enferm } \\
\text { UFSM }\end{array}$ & $\begin{array}{l}\text { O processo do trabalho educativo } \\
\text { do enfermeiro deve ser amparado } \\
\text { pelo dialogo e pelas vivencias dos } \\
\text { indivíduos, de modo que favoreça a } \\
\text { prevenção de doenças e a } \\
\text { promoção da saúde. Para isso, um } \\
\text { processo de trabalho } \\
\text { interdisciplinar é necessário. }\end{array}$ & $\begin{array}{c}\text { Pesquisa } \\
\text { bibliográfica. }\end{array}$ \\
\hline $\begin{array}{l}\text { Roecker; } \\
\text { Nunes; } \\
\text { Marcon; } \\
2013 . \\
2010-2010 . \\
\text { Brasil. }\end{array}$ & $\begin{array}{l}\text { O trabalho } \\
\text { educativo do } \\
\text { enfermeiro na } \\
\text { estratégia } \\
\text { saúde da } \\
\text { família }\end{array}$ & $\begin{array}{l}\text { Texto } \\
\text { Contexto } \\
\text { Enferm }\end{array}$ & $\begin{array}{l}\text { O desenvolvimento de educação } \\
\text { em saúde pelo enfermeiro é a } \\
\text { principal ferramenta para a } \\
\text { valorização do ser humano no } \\
\text { contexto da atenção primaria. } \\
\text { Espera-se que, o desenvolvimento } \\
\text { de atividades educativas, os } \\
\text { indivíduos possam também } \\
\text { desenvolver seu senso critico e } \\
\text { capacidade de intervir sobre sua } \\
\text { própria saúde. }\end{array}$ & $\begin{array}{c}\text { Estudo } \\
\text { descritivo e } \\
\text { exploratório. }\end{array}$ \\
\hline
\end{tabular}

Fonte: Autores (2016).

Dos 04 artigos analisados, a maior publicação se concentrou no ano de 2012, com duas publicações, seguido dos anos de 2011 e 2013 com uma publicação. Todos os quatro artigos selecionados foram publicados em periódicos diferentes, sendo eles: Revista de Enfermagem do Centro Oeste Mineiro, Revista da Escola de Enfermagem da USP, Revista de Enfermagem da UFSM e a Revista Texto e Contexto em Enfermagem. 
Cada um com seu objetivo, os artigos analisados trouxeram os seguintes resultados em relação à prática de educação em saúde: seu desenvolvimento ainda é cercado por dificuldades relacionadas com 0 processo administrativo e organizativo da atenção primária em que, quase sempre o enfermeiro é o responsável e o administrador da unidade, dificultando seu processo de trabalho assistencial. Além disso, para o pleno desenvolvimento das atividades educativas, os diversos profissionais que compõem a equipe precisam estar engajados, de forma que o processo de trabalho educativo desenvolva-se de forma interdisciplinar, onde todos buscam um mesmo objetivo. Sobre tudo, é imprescindível que a equipe conheça sua realidade de trabalho, permitindo assim, o desenvolvimento de atividades direcionadas aos casos mais emergentes e aos principais problemas presentes na área de abrangência e de atuação das equipes.

A educação em saúde insere-se no contexto de trabalho da enfermagem como forma de estabelecimento de uma relação de dialogo e reflexão junto aos usuários dos serviços de saúde, buscando conscientizar sobre as situações saúdedoença, motivando a comunidade a fortalecer e promover diariamente uma transformação pessoal de hábitos que fogem de contextos divergentes a uma vida saudável e que de preferencia a uma saúde de qualidade (SOUSA et al., 2010).

Assim, no âmbito da atenção primaria o enfermeiro é o responsável pelo desenvolvimento das ações de gerenciamento e de assistência aos pacientes, bem como, o desenvolvimento da educação em saúde, devendo assim, organizar um processo de trabalho que satisfaça todas as necessidades de saúde da população, reforçando juntamente com a equipe, a defesa do acesso universal, a integralidade da assistência, a resolutividade, bem como, a garantia da participação da comunidade nas decisões relativas à saúde (SILVA et al., 2012).

Apesar da necessidade do envolvimento e engajamento de toda a equipe para o desenvolvimento pleno da educação em saúde, o enfermeiro é o profissional com maior identificação, o qual deve comprometer-se com a função e realiza-la, tendo em vista que seu trabalho está intimamente ligado a ela, comparado ao trabalho realizado pelos demais profissionais da atenção primária (ACIOLI, 2008).

Gonçalves et al. (2011), em seus estudos trazem que o delineamento do contexto de trabalho da educação em saúde deve estar baseada em uma politica de ações que distancie o olhar e escuta centrado nas doenças para um trabalho centrado no sujeito, suas condições de trabalho, moradia e relacionamentos com a 
comunidade em um todo, conhecendo seus problemas e o orientando quanto a mudança de hábitos para uma melhoria da qualidade de vida.

Portanto, a promoção da saúde torna-se uma estratégia para o enfrentamento de diversos problemas presentes nas famílias e que afetam a população mundo a fora. É imprescindível o seu desenvolvimento, uma vez que representa um dos quatro níveis de atenção obrigatórios lançados pelo Ministério da Saúde, dentre a prevenção, recuperação e a reabilitação de doenças (LOPES et al., 2013).

\section{CONCLUSÕES}

Concluído do estudo sobre a educação em saúde no contexto de trabalho do enfermeiro, pode-se considerar que o desenvolvimento de atividades educativas ainda é incipiente, tendo em vista uma série de condicionantes que impede a sua execução na prática.

Percebe-se ainda que, o ambiente da atenção primária em saúde representa o melhor espaço para o pleno funcionamento das atividades educativas, uma vez que a difícil tarefa de se conhecer a região trabalhada, os seus problemas e os seus agravos são facilitados tendo em vista a sua menor extensão, bem como, a presença de uma equipe multidisciplinar e que teoricamente estará a disposição para o desenvolvimento das atividades.

Por fim, conclui-se que o enfermeiro é o profissional com a maior proximidade do tema de educação em saúde, sendo o responsável pelo seu desenvolvimento. Porém, seu processo de trabalho dentro da atenção primária é marcado por uma sobrecarga de tarefas, devendo ser o administrador da unidade, o supervisor das atividades da equipe, o responsável pelo processo burocrático e pelo direcionamento das ações, devendo ainda, administrar seu tempo para realização de atividades assistenciais privativas de sua categoria profissional, fazendo com que, o planejamento de atividades e ações de educação em saúde seja mantido de lado, executando no seu dia-a-dia apenas um trabalho centrado no modelo curativo e não de prevenção de doenças e de promoção da saúde.

\section{REFERÊNCIAS}


ACIOLI, S. A prática educativa como expressão do cuidado de saúde pública.

Revista Brasileira de Enfermagem, v. 61, n. 1, p. 117-121, 2008.

ALVES, G. G.; AERTS, D. As práticas educativas em saúde e a Estratégia Saúde da Família. Ciência \& Saúde Coletiva, v. 16, n. 1, p. 319-325, 2011.

FERREIRA, V. F. et al. Educação em saúde e cidadania: revisão integrativa. Trab. Educ. Saúde, v. 12 n. 2, p. 363-378, 2014.

GIJSEN, L. I. P. S.; KAISER, D. E. Enfermagem e educação em saúde em escolas no Brasil: revisão integrativa da literatura. Cienc Cuid Saude, v. 12, n. 4, p. 813-821, 2013.

GONÇALVES, A. M. et al. Promoção da saúde no cotidiano das equipes de saúde da família: uma prática intersetorial? R. Enferm. Cent. O. Min., v. 1, n. 1, p. 94-102, 2011.

LOPES, M. S. V. et al. Promoção da saúde na percepção de profissionais da estratégia saúde da família. Rev Rene., v. 14, n. 1, p. 60-70, 2013.

OLIVEIRA, R. L.; SANTOS, M. E. A. Educação em saúde na estratégia saúde da família: conhecimentos e práticas do enfermeiro. Revista Enfermagem Integrada Ipatinga, v. 4, n. 2, p. 833-844, 2011.

ROECKER, S; NUNES, E. F. P. A.; MARCON, S. S. O trabalho educativo do enfermeiro na estratégia saúde da família. Texto Contexto Enferm, v. 22, n. 1, p. 157-65, 2013.

ROECKER, S.; BUDÓ, M. L. D.; MARCON, S. S. Trabalho educativo do enfermeiro na Estratégia Saúde da Família: dificuldades e perspectivas de mudanças. Rev Esc Enferm USP, v. 46, n. 3, p. 641-649, 2012.

SILVA, L. D. et al. O enfermeiro e a educação em saúde: um estudo bibliográfico. Rev Enferm UFSM, v. 2, n. 2, p. 412-419, 2012.

SILVA, S. A. et al. Atividades desenvolvidas por enfermeiros no PSF e dificuldades em romper o modelo flexneriano. R. Enferm. Cent. O. Min., v. 1, n. 1, p. 30-39, 2011.

SOUSA, L. B. et al. Práticas de educação em saúde no Brasil: a atuação da enfermagem. Rev. enferm. UERJ, v. 18, n. 1, p. 55-60, 2010.

VIANA, D. M. et al. A educação permanente em saúde na perspectiva do enfermeiro na estratégia de saúde da família. Rev. Enferm. Cent. O. Min., v. 5, n. 2, p. 16581668, 2015. 